\title{
ELLIPSOMETRY OF POLYCRYSTALLINE IRON ELECTRODES IN ALKALINE SOLUTIONS CONTAINING CHLORIDE IONS UNDER DIFFERENT ELECTROCHEMICAL CONDITIONS
}

\author{
S. Juanto, J. O. Zerbino, M. I. Miguez*, J. R. Vilche and A. J. Arvia ${ }^{\dagger}$
}

Instituto de Investigaciones Fisicoquímicas Teóricas y Aplicadas INIFTA, Facultad de Ciencias Exactas, Universidad Nacional de La Plata, Sucursal 4, Casilla de Correo 16, (1900) La Plata, Argentina

(Received 31 March 1987)

\begin{abstract}
The ellipsometric and voltammetric responses of iron in $0.04 \mathrm{M} \mathrm{NaOH}+x \mathrm{M} \mathrm{NaCl}(0 \leqslant x \leqslant 0.3)$ are investigated. Thiree main processes, barrier layer formation, outer layer formation and pitting corrosion which depend differently on the presence of $\mathrm{NaCl}$ can be distinguished. The first process becomes practically independent of $\mathrm{NaCl}$ concentration. Otherwise, under certain conditions $\mathrm{NaCl}$ increases the charge associated with the outer layer formation through pitting. The dependence of the latter on $\mathrm{NaCl}$ concentration is in agreement with data earlier reported in the literature. A relation among the three processes is discussed in terms of competitive anion adsorption on iron specimen and formation of redox couples within the hydrous oxide layer produced on iron.
\end{abstract}

\section{INTRODUCTION}

The formation of passivating layers on iron in base solution and their structure in the absence of oxygen have been the matter of many publications in the last few decades, particularly after the development of optical reflection techniques. The literature on the subject is reviewed in references[1-3]. However, despite these contributions the corrosion and passivation of iron still can not be completely handled as the number of variables involved in those processes is larger than earlier thought. The behaviour of iron in alkaline solution can be roughly described by taking into account whether aggressive anions are absent or present in the aqueous solutions.

In the absence of aggressive anions, in-situ Raman spectroscopy studies of iron passivation in $1 \mathrm{M} \mathrm{KOH}$ during oxidation-reduction cycles [4] were interpreted through the formation of $\mathrm{Fe}_{3} \mathrm{O}_{4}$ whereas in other cases $[5,6]$ the surface layer produced at $1 \mathrm{mVs}^{-1}$ appeared to be composed of $\delta-\mathrm{FeOOH}$ which by subsequent cycling is converted to $\mathrm{Fe}_{3} \mathrm{O}_{4}$. Likewise, the spectra of the outer passivation layer after prolonged potential cycling at $50 \mathrm{mV} \mathrm{s}^{-1}$ was assigned to $\alpha$-FeOOH. Ellipsometric measurements of iron cycled galvanostatically in $0.05 \mathrm{M} \mathrm{NaOH}$ show that a low density $\mathrm{FeOOH}$ layer builds up progressively over an inner compact $\mathrm{Fe}_{3} \mathrm{O}_{4}$ barrier layer[7]. On the other hand, the electrochemical and ellipsometric transient behaviour of the anodic film growth on iron in $0.05 \mathrm{M}$ $\mathrm{NaOH}$ at different potentials in the passive region after the electrode potential was rapidly changed at $80 \mathrm{~V} \mathrm{~s}^{-1}$ from a fixed potential in the $H E R$ region concluded

* Present address, Instituto Nacional de Tecnologia Industrial (INTI), Sector Electroquímica Aplicada. Casilla de Correos 157, (1650) San Martín, Argentina.

† Author to whom correspondence should be addressed. that the passive film formed for times longer than $2 \mathrm{~s}$ can be identified as $\mathrm{Fe}_{3} \mathrm{O}_{4}[8]$. Otherwise, the examination of passive anodic oxides on iron in $1 \mathrm{M} \mathrm{NaOH}$ by X-ray photoelectron spectroscopy after specimen preparation and transfer in an oxygen-free closed system [9] reveals that the film potentiostatically formed consists of an inner $\mathrm{FeO}, \mathrm{Fe}(\mathrm{OH})_{2}$ layer and an outer $\mathrm{Fe}_{2} \mathrm{O}_{3}$ layer. The latter should be absent at sufficiently negative potentials. Most recently potential-modulated reflectance spectra of the passive film on iron in $0.1 \mathrm{M} \mathrm{NaOH}$ at different potentials after an anodic sweep at $10 \mathrm{mVs}^{-1}[10]$ at high positive potentials were assigned to magnetite, hematite, or both, while the film in the initial prepassive region exhibits the presence of $\mathrm{Fe}^{2+}$ ion. Recent attempts to correlate ellipsometric and voltammetric results in either $\mathrm{NaOH}$ or $\mathrm{Ca}(\mathrm{OH})_{2}$ solutions at the same pH led to the conclusion that the structure of the passivating layer and its properties change also appreciably with the cation in solution $[3,11]$.

Current transients and also optical parameters and thickness of passive films on iron in $\mathrm{NaOH}$ solution in the presence of $\mathrm{NaCl}$ at $\mathrm{pH} 12$ indicate that pitting can occur only when the surface layer is not yet sufficiently consolidated[12], probably because it contains a large amount of incorporated water. At fixed concentration of $\mathrm{NaCl}$ both electrode potential and passive film water content contribute to passivity breakdown. The high pitting potentials of iron in $\mathrm{NaOH}$ solutions containing $\mathrm{NaCl}$ within the $10-13 \mathrm{pH}$ range were interpreted as due to a chemical depassivation of the $\gamma-\mathrm{Fe}_{2} \mathrm{O}_{3}$ layer accompanied by the accumulation of chloride ions at the metal-solution interface[13].

These different views on fundamental aspects of the corrosion and passivation of iron in base solutions suggested the convenience of extending the previous work on the correlation of ellipsometry-voltammetry data of iron in $\mathrm{NaOH}$ by adding different concentrations of $\mathrm{NaCl}$. 


\section{EXPERIMENTAL}

The working electrodes consisted of circular $\left(0.785 \mathrm{~cm}^{2}\right)$ high purity polycrystalline iron samples ("Specpure", Johnson Matthey Chemicals Ltd.) supported on PTFE holders. They were previously polished with 400 and 600 grade emery papers and $1.0,0.3$, and $0.05 \mu$ grits alumina-acetone suspensions on polishing cloths (Microcloth), then thoroughly rinsed with thrice distilled water, and finally, held for $5 \mathrm{~min}$ at $E=$ $-1.36 \mathrm{~V}$, that is in the potential region of net hydrogen evolution to attain a reproducible electroreduced metal surface[ $[3,11]$.

A three compartment electrolysis glass cell was employed to lodge the working electrode, reference electrode and counterelectrode. The working electrode was horizontally placed at the bottom of the main compartment, which was provided with two plane glass windows, which were adequated for ellipsometric measurements. The potential of the working electrode was measured against a reversible hydrogen electrode in the cell solution but in the text they are referred to the NHE scale. The counterelectrode was a large area spiral-shaped $\mathrm{Pt}$ wire.

Electrochemical and ellipsometric runs were made in $0.04 \mathrm{M} \mathrm{NaOH}+x \mathrm{M} \mathrm{NaCl}(0 \leqslant x \leqslant 0.3)$ solutions, at $25^{\circ} \mathrm{C}$ under $\mathrm{N}_{2}$ gas saturation. The electrolyte solutions were prepared from a.r. (p.a. Merck) reagents and thrice distilled water previously boiled to remove $\mathrm{CO}_{2}$.

The electrolysis cell was assembled in a Rudolph Research type 437-02/200 B manual ellipsometer (maximum resolution $0.01^{\circ}$ ) provided with a $150 \mathrm{~W}$ tungsten lamp with filter (5461 $\AA$ ) and a RCA 1P 21 photomultiplier. The incidence light beam angle was fixed at $69^{\circ}$ and that of the compensator at $135^{\circ}$. The complex refractive index of the substrate $\left(\bar{n}_{s}=n_{s}-i k_{s}\right)$ at $5461 \AA$ for polished iron electrode held at $-1.36 \mathrm{~V}$ obtained from polarizer $\left(P_{0}\right)$ and analyzer $\left(A_{0}\right)$ readings was coincident with data previously reported in the literature $[14,15]$.
The ellipsometric characteristics of the working electrode surface were followed by perturbing with different potential-time programmes. Procedure A implied an electrode pretreatment with either a single (STPS) or a repetitive (RTPS) triangular potential sweep at $v=20 \mathrm{Vs}^{-1}$ between cathodic $\left(E_{s, c}\right)$ and anodic $\left(E_{s, a}\right)$ switching potentials suitable to produce a net anodic layer on the electrode surface. Immediately afterwards the anodic layer was held during a certain time $(\tau)$ at either $E_{s . a}$ (potentiostatic stabilization and growth) or $E_{s, c}$ (potentiostatic electroreduction). Procedure B was similar to procedure A, but after holding the potential at either $E_{s . a}$ or $E_{s . c}$ for the time $\tau$, the current was switched off during different times $\tau_{0}$, and immediately afterwards the voltammetric scan was continued on from the corresponding open circuit potential.

The ellipsometric readings ( $P$ and $A$ ) of the electrode covered with anodic products were made under either extinction condition or by following the change of $\mathbf{P}$ through the variation of the reflected light intensity, depending whether the time window ( $t$ and $\tau_{0}$ ) values of each run were greater or lower than $30 \mathrm{~s}$, respectively.

For the sake of comparison, voltammograms in the $0.002 \leqslant v \leqslant 20 \mathrm{~V} \mathrm{~s}^{-1}$ range were also run to follow anodic and cathodic contributions in the different potential ranges.

\section{RESULTS}

\section{Electrochemical data}

The STPS voltammograms of polycrystalline iron in $0.04 \mathrm{M} \mathrm{NaOH}$ (Fig. 1a) and $0.04 \mathrm{M} \mathrm{NaOH}+0.05 \mathrm{M}$ $\mathrm{NaCl}$ (Fig. 1b) run between about -1.26 and ca $0.04 \mathrm{~V}$ at different $v$ show four anodic peaks (I, II, III, and III') and two cathodic peaks (IV and V). After ten potential cycles the increase in charge of peaks III and IV and the appearance of a new cathodic contribution (peak IV')

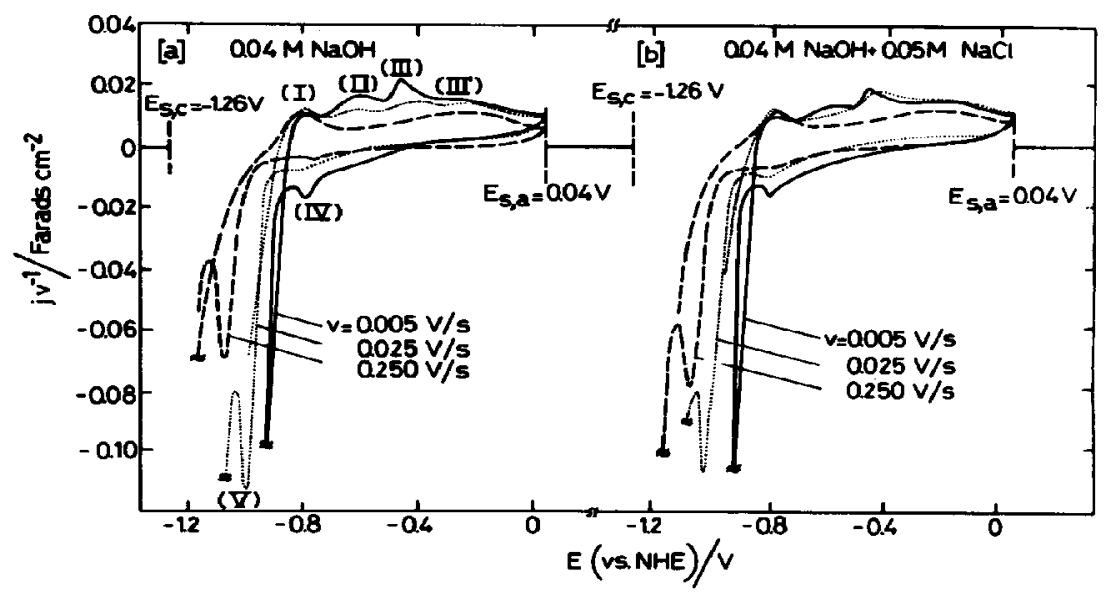

Fig. 1. Single triangular potential sweep (STPS) voltammograms at different $v$ between $E_{s, c}=-1.26 \mathrm{~V}$ and $E_{s, a}=0.04$ V. (a) $0.04 \mathrm{M} \mathrm{NaOH}$; (b) $0.04 \mathrm{M} \mathrm{NaOH}+0.05 \mathrm{M} \mathrm{NaCl}$. 


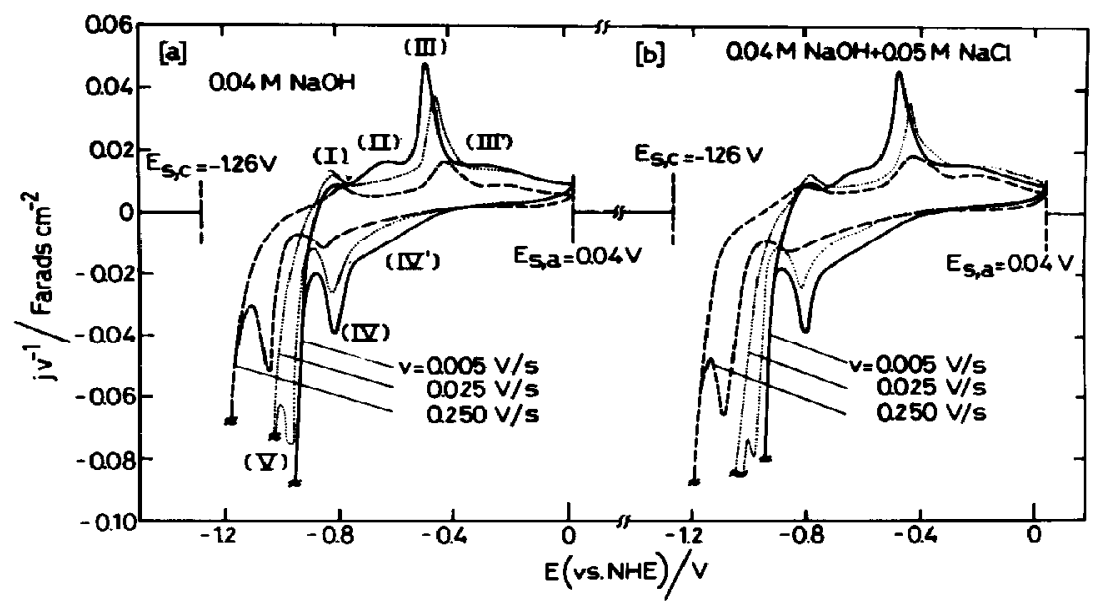

Fig. 2. $j / v v s$ potential plots after 10 potential cycles at different $v$ between $E_{s, c}=-1.26 \mathrm{~V}$ and $E_{s, a}=0.04 \mathrm{~V}$. (a) $0.04 \mathrm{M} \mathrm{NaOH}$; (b) $0.04 \mathrm{M} \mathrm{NaOH}+0.05 \mathrm{M} \mathrm{NaCl}$.

can be noticed (Fig. 2). Conjugated peaks I-II/V are related to the electroformation and electroreduction of the prepassive iron hydroxide layer and the complex conjugated peaks III-III'/IV-IV' have been assigned to the reaction $\mathrm{Fe}(\mathrm{II}) \rightleftharpoons \mathrm{Fe}(\mathrm{III})+\mathrm{e}^{-}$in the passive film[3]. The voltammetric contours are substantially modified either in going from the first to the tenth sweep at a constant $v$, or for a constant number of cycles by just changing $v$. Conversely, only minor voltammetric changes are caused by the presence of $\mathrm{NaCl}$. This can be taken as a preliminary indication that the mechanism of the passive layer formation and its corresponding composition is to a great extent determined by the local concentration of $\mathrm{OH}^{-}$ions.

\section{Ellipsometric data in $0.04 \mathrm{M} \mathrm{NaOH}$}

The transient ellipsometric response resulting under procedure $A$ for iron in $0.04 \mathrm{M} \mathrm{NaOH}$ solution $\left(E_{s, c}=\right.$ $-1.26 ;-0.2 \mathrm{~V} \leqslant E_{\text {s.a }} \leqslant 0.65 \mathrm{~V}$; and $2 \leqslant \tau \leqslant 5 \mathrm{~s}$ ) (Fig. 3) shows an initial fast decrease of $\delta P$, to attain a nearly constant value after about $2 \mathrm{~s}$. This result agrees with earlier data obtained from extinction measurements under open circuit conditions[3]. After the anodic oxide formation during the time $\tau$ the $\delta P$ vs time plot shows a large linear increasing portion and at the end a limiting value of $\delta P$ different from the initial one. This means that electroreduction products remain on the metal surface even at relatively high negative potentials (Fig. 3a). The change in $\delta P$ under a potential holding is accompanied by a definite change in current. Thus, for the anodic potential step a monotonic anodic current decrease can be observed, whereas for the cathodic step at short times a cathodic hump superposed to the base current associated with the HER can be noticed (Fig. $3 b)$. For a constant $\tau$ the charge density estimated from the cathodic hump, $Q_{c}$, after correction for the e.d.1. charging and HER contributions, increases reasonably linearly with $E_{s, a}($ Fig. 4). From this plot it results that $Q_{c} \rightarrow 0$ for $\left(E_{s, a}\right)_{Q_{1}=0} \simeq-0.68 \mathrm{~V}$.

Similar runs made including the current switching off during $\tau_{0}=4 \mathrm{~min}$ (procedure $B$ ) for an oxide layer

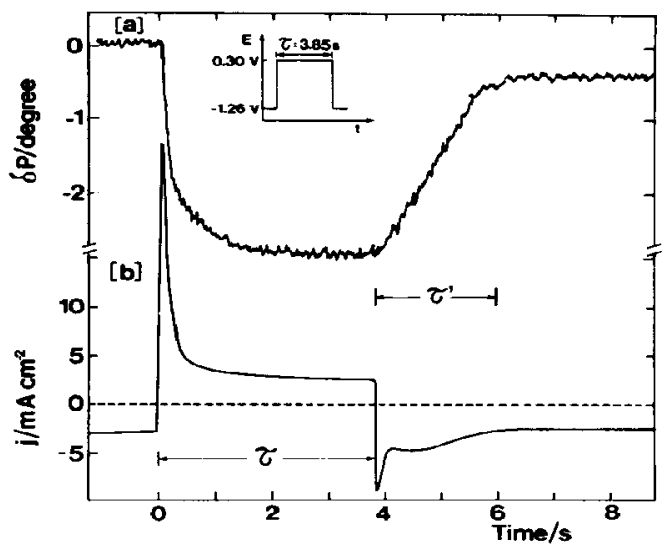

Fig. 3. Dynamic ellipsometric (a) and current transient (b) responses in $0.04 \mathrm{M} \mathrm{NaOH}$ during a potential step from $E_{s, c}$ $=-1.26 \mathrm{~V}$ to $E_{s, a}=0.30 \mathrm{~V}$ including a holding time $\tau$ $=3.85 \mathrm{~s}$ at $E_{s, a}$

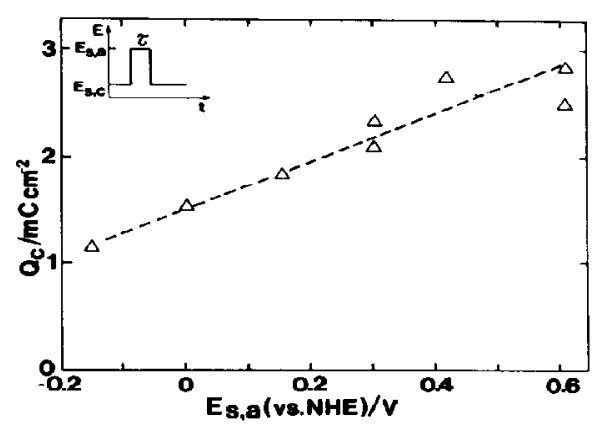

Fig. 4. Dependence of anodic potential holding at $E_{s, o}$ for $3.85 \mathrm{~s}$ on the charge $Q_{\mathrm{c}}$ of the cathodic jump superposed to the hydrogen evolution reaction baseline at $E_{s, c}=-1.26 \mathrm{~V}$ in $0.04 \mathrm{M}$ NaOH. 
electroformed at $0.61 \mathrm{~V}$ (Fig. 5) show that the potential firstly decays to a minimum value of about $-0.81 \mathrm{~V}$ after about $40 \mathrm{~s}$, and later gradually increases approching a value close to $-0.69 \mathrm{~V}$ after $4 \mathrm{~min}$. By switching off the current (Fig. 6) $\delta P$ slightly increases for a few seconds, and finally reaches a constant value substantially lower than the initial one. Afterwards, the following cathodic potential step reproduces the behaviour already described for Figs 1, 3 and 4 . This effect which becomes more remarkable by increasing the number of successive runs, can he taken as a first indication that products remaining on the electrode

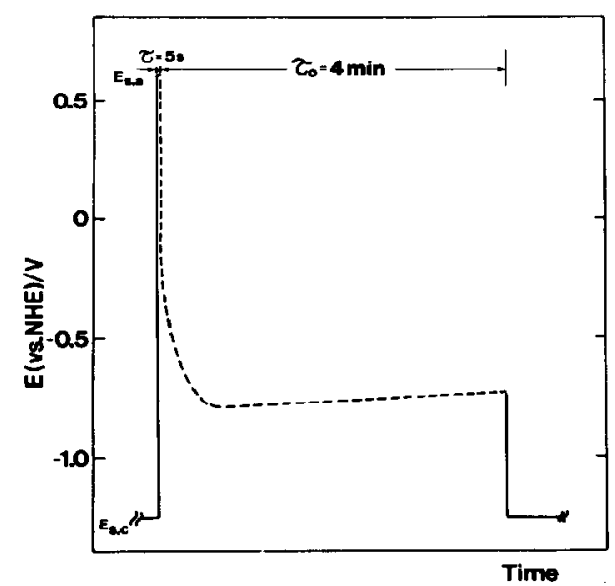

Fig. 5. Open circuit potential evolution after a potential step from $E_{\mathrm{s}, c}=-1.26 \mathrm{~V}$ to $E_{s, a}=0.61 \mathrm{~V}$ including a $5 \mathrm{~s}$ holding time at $E_{s, a}$ in $0.04 \mathrm{M} \mathrm{NaOH}$.

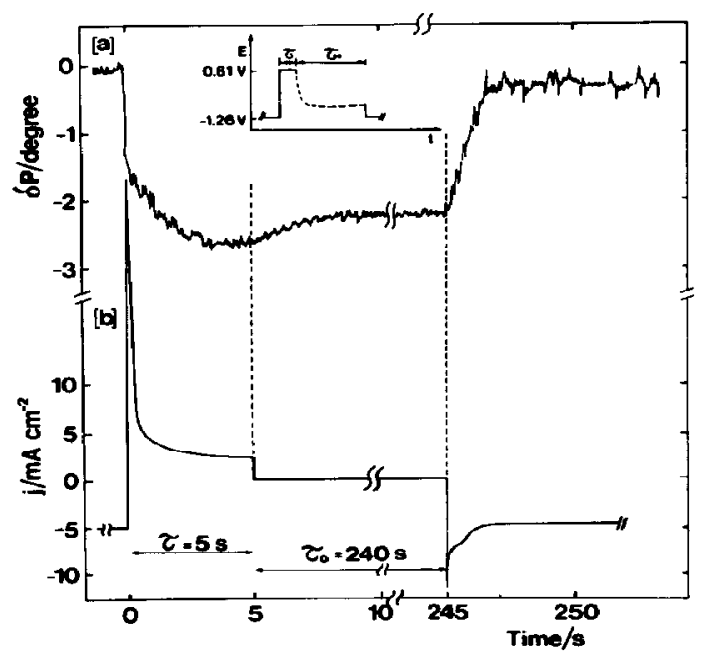

Fig. 6. Dynamic ellipsometric data (a) and current transient (b) in $0.04 \mathrm{M} \mathrm{NaOH}$ during a potential programme which includes a potential step at $E_{s, a}=0.61 \mathrm{~V}$ during $\tau=5 \mathrm{~s}$, open circuit during $\tau_{0}=4 \mathrm{~min}$, and potential stepped to $E_{s, c}$ $=1.26 \mathrm{~V}$ as indicated in the figure.

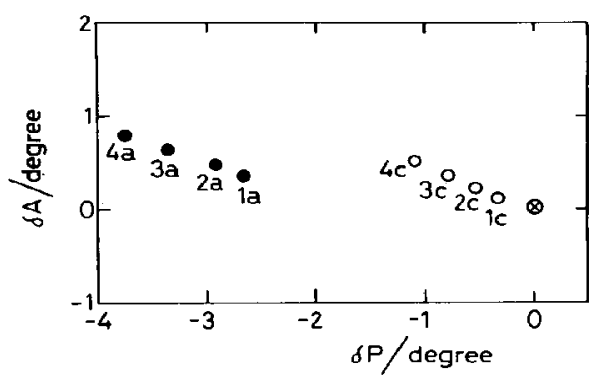

Fig. 7. $P$ vs $A$ plot for the surface film at $E_{s, a}=0 \mathrm{~V}$ (full symbols) and $E_{s, c}=-1.26 \mathrm{~V}$ (open symbols) from the 1st to the 4th potential scans at $v=20 \mathrm{Vs}^{-1}$ in $0.04 \mathrm{M} \mathrm{NaOH}$.(8) identifies freshly electroreduced iron electrode held at $E_{s, c}$ during $10 \mathrm{~min}$.

surface after electroreduction presumably undergo changes in both composition and structure. The plot of ellipsometric data (Fig. 7) shows a clear difference between the behaviour of the layer held at either 0 or $-1.26 \mathrm{~V}$. Likewise, during the successive runs for particular values of $E_{s, a}$ and $E_{s, c}$ the ellipsometric data shifts in the same direction. These results suggest that the oxide layer remaining on the surface at high negative potentials progressively accumulates during cycling and its presence has little influence on the subsequent electrooxidation of the base metal in the following anodic potential step. It should be observed that the scattering of ellipsometric data is lower than $10 \%$.

\section{Ellipsometric data in $0.04 \mathrm{M} \mathrm{NaOH}$ containing $\mathrm{NaCl}$}

For $E_{s, a}$ values exceeding the critical pitting potential of iron in base solutions containing $\mathrm{NaCl}$ (Fig. $8)[12,16]$ the dynamic behaviour of $\delta P$ and $j$ is at first sight different from that depicted in Fig. 6, and it depends whether the run is made under anodic potential step or open circuit conditions. In the first case a sharp initial decrease in $\delta P$ and also in $j$ after the e.d.1. charging, comparable to that already observed in the absence of $\mathrm{Cl}^{-}$ions can be noticed, whereas $\tau$ increases $\delta P_{\text {app }}$ and $j$ also increase due to pitting caused by chloride ions. These effects become more remarkable during successive potential steps. Otherwise, for the cathodic potential step initially the situation is comparable to that shown in Fig. 6, but as the number of successive potential steps increases, the contribution of pitting becomes more relevant. Under open circuit conditions a steady pitting corrosion operates which reflects through the constancy of $\delta P$ and $j$ values. Hence, for a preset potential step it is reasonable to expect that both $\delta P$ and $Q_{c}$ change linearly with the potential of anodic step (Fig. 9). The extrapolation of $\delta P$ vs $E_{s, a}$ (Fig. 9a) and $Q_{c}$ vs $E_{s, a}$ (Fig. 9b), at $\delta P \rightarrow 0$ and $Q_{c} \rightarrow 0$ yield $E_{\delta P}^{0}=-0.73 \mathrm{~V}$ and $E_{Q_{\mathrm{c}}}^{0}=-0.66 \mathrm{~V}$, respectively. On the other hand, the change of $P$ at high negative potentials $\left(\Delta P_{c}\right)$ measured after the anodic potential step (Fig. 10) also fits a linear $\Delta P_{c}$ vs $E_{s, a}$ relationship, whose extrapolation to $\Delta P_{\mathrm{c}} \rightarrow 0$ approaches $E_{\Delta P_{c}}^{\mathrm{o}} \simeq-0.55 \mathrm{~V}$. Obviously, the reproducibility of results in the $\mathrm{NaCl}$ solutions is lower than in $\mathrm{NaCl}$ free base due to pitting corrosion. 


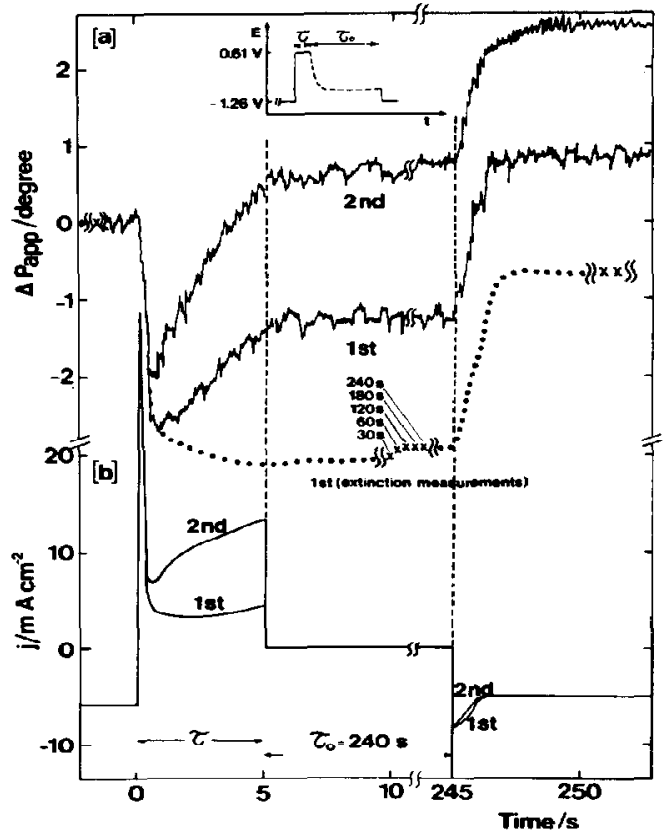

Fig. 8. Dynamic ellipsometric measurements (a) and current transient (b) in $0.04 \mathrm{M} \mathrm{NaOH}+0.05 \mathrm{M} \mathrm{NaCl}$. Each cycle of the potential programme as indicated in figure.

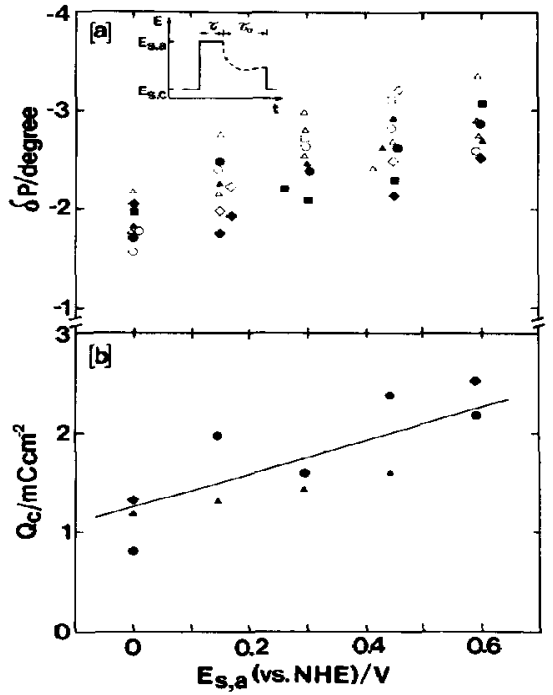

Fig. 9. (a) Comparison between the dependences of $E_{s . a}$ on the dynamic ellipsometric (open symbols) and extinction measurements (full symbols) data. The potential programme consists of a potential step at different $E_{\text {s.a }}$ during $2 \mathrm{~s}$, open circuit during $4 \mathrm{~min}$, and potential stepped to $E_{s . c}=-1.26 \mathrm{~V}$. (b) Dependence of $E_{s . a}$ on the properly corrected $Q_{c}$ at $E_{s . c}$. $(\Delta, \Delta) 0.04 \mathrm{M} \mathrm{NaOH} ;(O, \infty), 0.04 \mathrm{M} \mathrm{NaOH}+0.01 \mathrm{M} \mathrm{NaCl}$; $(0, \bullet) 0.04 \mathrm{M} \mathrm{NaOH}+0.05 \mathrm{M} \mathrm{NaCl} ;(\square, \square) 0.04 \mathrm{M} \mathrm{NaOH}$ $+0.3 \mathrm{M} \mathrm{NaCl}$.

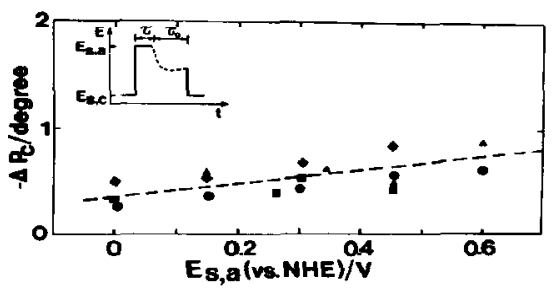

Fig. 10. Dependence of the anodic potential step value on the variation of $P$ measured at $E_{s, c}=-1.26 \mathrm{~V}$ after the potential programme indicated in Fig. 9. (4)0.04 M NaOH; ( $) 0.04 \mathrm{M}$ $\mathrm{NaOH}+0.01 \mathrm{M} \mathrm{NaCl}$; (॰) $0.04 \mathrm{M} \mathrm{NaOH}+0.05 \mathrm{M} \mathrm{NaCl}$; (a) $0.04 \mathrm{M} \mathrm{NaOH}+0.3 \mathrm{M} \mathrm{NaCl}$.

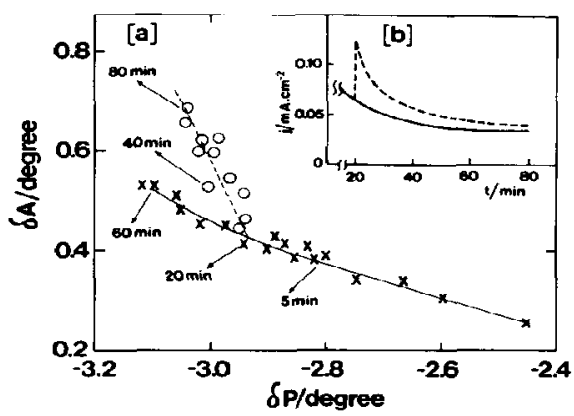

Fig. 11. Comparative $P$ vs $A$ plots (a) and current transient (b) in $\mathrm{NaCl}$ free [full lines, $(x)$ and $\mathrm{NaCl}$ added solutions [dashed lines, (o)] in $0.04 \mathrm{M} \mathrm{NaOH}$ solutions during the potential holding at $0.03 \mathrm{~V}$ after a potential scan at $v$ $=20 \mathrm{Vs}^{-1}$ from $E_{\mathrm{s}, c}=-1.36 \mathrm{~V}$. The $\mathrm{NaCl}$ addition up to $0.05 \mathrm{M}$ was made after $20 \mathrm{~min}$ holding time at $E_{s, a}=0.03 \mathrm{~V}$.

The time variation of the ellipsometric parameters by holding a constant applied potential depends strongly on the presence of $\mathrm{NaCl}$ in solution. This is clearly seen by adding $\mathrm{NaCl}$ up to $0.05 \mathrm{M}$ in $0.04 \mathrm{M}$ $\mathrm{NaOH}$ after the ellipsometric readings at $E_{s, a}=0.03 \mathrm{~V}$ (Fig. 11). The separation of the corresponding $\delta A v S$ $E_{s, a}$ and $\delta P$ vs $E_{s, a}$ plots in the absence and in the presence of added $\mathrm{NaCl}$ increases with time (Fig. 11a). On the other hand, after the incorporation of $\mathrm{NaCl}$ the current transient increases as compared to that recorded in plain base solution (Fig. 11b).

\section{DISCUSSION}

Electrochemical and ellipsometric data show that the growth of the passive film on iron in alkaline solution in the absence of $\mathrm{NaCl}$ involves two distinguishable stages and correspondingly, the formation of two juxtaposed layers $[3,17-20]$. According to the present results the inner layer (barrier layer) in contact with the metal surfaces is firstly formed, at a relatively low rate, as derived from current transients and first voltammetric cycles, the latter being characterized by the prevalence of peaks I and II. Conversely, the outer layer although subsequently formed, exhibits a relatively large growth rate. Thus, the contribution of 
peak III related to the formation of a hydrous porous Fe(III)-oxide structure becomes increasingly important with the number of voltammetric cycles. Both the increase in the anodic polarization and cathodic electroreduction time promote the progressive increase of the outer layer charge. The present results also confirm that during the voltammetric cycles (Fig. 2) the partial electroreduction of the inner layer can be accomplished. This is in agreement with the fact that the extrapolation of the $\delta P$ vs $E_{s, a}$ plot to $\delta P \rightarrow 0$, occurs for a value of $E$ slightly more positive than that of the voltammetric peak I related to $\mathrm{Fe}(\mathrm{OH})_{2}$ monolayer formation. As a matter of fact, the complete electroreduction of the barrier layer takes place rather slowly in the potential range of peak $V[3,11]$. Otherwise, the barrier layer can be regenerated already after 1.5-2.0 s after the anodic potential step has been applied. On the other hand, the outer layer should imply a hydrous structure with a large initial content of Fe(III) species, which in turn are able to participate in relatively fast redox processes[3]. It should be noticed that recent voltammetric data obtained with iron hydroxide layers precipitated on platinum electrodes are in agreement with these conclusions $[21,22]$.

The precedent description of iron passivation in base solution can be useful to interpret the influence of $\mathrm{NaCl}$ in the entire reaction. Thus, it appears that the presence of $\mathrm{NaCl}$ at least in the concentration range covered by this work, remains unnoticed in the time range associated with the formation of the barrier layer. A different situation arises in the time range related to the growth of the outer layer coupled to pitting corrosion, the latter becoming noticeable only after the barrier layer has been near completely formed.

The reaction yielding the initial thin $\mathrm{Fe}(\mathrm{OH})_{2}$ layer is determined by the high adsorbability of $\mathrm{OH}^{-}$ions and can be written as follows $[21,23,24]$ :

$$
\mathrm{Fe}+2\left(\mathrm{OH}^{-}\right)=\left[\mathrm{Fe}(\mathrm{OH})_{2}\right]_{\mathrm{I}}+2 \mathrm{e}^{-} \text {, }
$$

which later transforms into $\mathrm{Fe}_{3} \mathrm{O}_{4}$ layer (barrier layer) as the potential increases. The complex nature of the overall reaction (1) was discussed in detail in previous publications $[23,24]$.

The growth of the outer layer (II) implies the formation of $\mathrm{Fe}(\mathrm{III})$ species under the form of a hydrous Fe(III) oxy-hydroxide layer. The correspond- series of reactions:

$$
\begin{aligned}
\mathrm{Fe}+3\left(\mathrm{OH}^{-}\right) \stackrel{-\left(2 \mathrm{e}^{-}\right)}{\rightleftharpoons} & {\left[\mathrm{Fe}(\mathrm{OH})_{2}\right]_{\mathrm{I}}+\mathrm{OH}^{-} } \\
& \stackrel{-\left(\mathrm{e}^{-}\right)}{\rightleftharpoons}\left[\mathrm{Fe}(\mathrm{OH})_{3}\right]_{\mathrm{II}},
\end{aligned}
$$

where the brackets denote hydrous species.

Finally, pitting corrosion requires a competitive interaction between $\mathrm{Cl}^{-}$and $\mathrm{OH}^{-}$ions with layers I and $I I$ and the proper iron surface. This can be written as follows:

$$
\begin{aligned}
2\left[\mathrm{Fe}(\mathrm{OH})_{2}\right]_{1}+3 \mathrm{Cl}^{-}= & {\left[\mathrm{FeCl}_{3}\right]_{1}+\left[\mathrm{Fe}(\mathrm{OH})_{2}\right]_{1} } \\
& +2 \mathrm{OH}^{-}+\mathrm{e}^{-}, \\
{\left[\mathrm{FeCl}_{3}\right]_{1}+3 \mathrm{OH}^{-}=} & {\left[\mathrm{Fe}(\mathrm{OH})_{3}\right]_{11}+3 \mathrm{Cl}^{-} . }
\end{aligned}
$$

Therefore, the presence of $\mathrm{Cl}^{-}$ion can promote the increase of the outer layer charge, and in this case, the induction time for pitting can be related to the adsorption of $\mathrm{Cl}^{-}$ion. The outer layer, whose thickness increases during potential cycling $[3,13]$, consists of either a very porous film containing a considerable amount of electrolyte or a film of electrolyte containing partially dissolved reaction products. Reaction (3a) can be, in principle, supported by recent measurements employing radiotracer techniques, in borate buffer, which indicate adsorption and absorption of chloride ions on passive iron[25]. The time constant for the chloride adsorption is about $1 \mathrm{~min}$, while that related to the chloride absorption into the passive layer is in the order of $60 \mathrm{~min}$. The latter process is controlled by diffusion and it increases linearly with potential. However, in contrast to these conclusions comparable studies made by Auger electrospectroscopy and $X$-ray photoelectron spectroscopy[26] were unable to detect $\mathrm{Cl}^{-}$jon incorporation into the oxide film. In addition it should be mentioned that in these optical studies no film thinning caused by $\mathrm{Cl}^{-}$ion could be observed, a fact which seems to occur as reported in an earlier work [27].

As discussed in early work [3] during the voltammetric cycling the following reversible reaction:

$$
\mathrm{e}^{-}+[\mathrm{Fe}(\mathrm{III})](\text { layer II })=[\mathrm{Fe}(\mathrm{II})](\text { layer II), }
$$

takes place at the outer layer, so that the various processes above described can be summarized in the following reaction scheme:

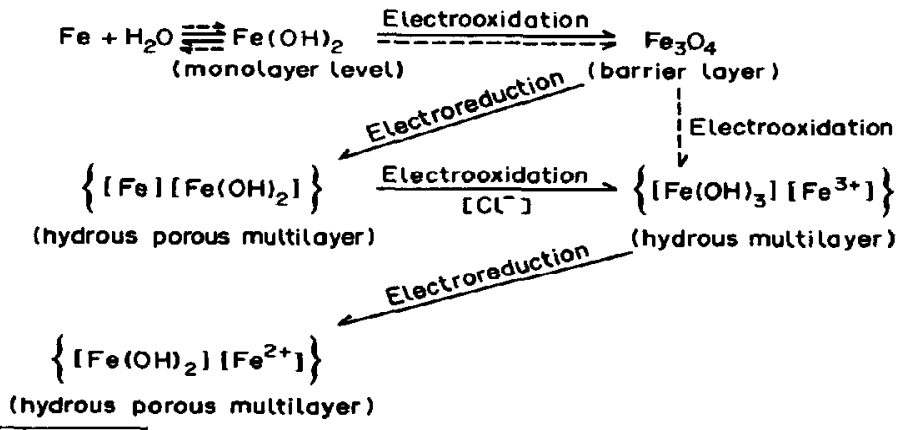

ing reaction occurs through the electro-oxidation of $\mathrm{Fe}(\mathrm{OH})_{2}$ which is immediately replenished. The overall process can be expressed in a simple way by the
Full arrows indicate the reaction pathway under potential cycling conditions, while dashed arrows show the electro-oxidation process during an anodic 
potential step. At large potential holding times in the passive region, the $\left[\mathrm{Fe}(\mathrm{OH})_{3}\right]$ hydrous species (layer II) tends to a $[\mathrm{FeOOH}]$ layer. Similarly, the inner portion of the outer layer II after prolonged potential cycling can be considered also as constituted mainly by [FeOOH] species.

According to these reactions the relative amount of layers I and II should be remarkably dependent on the presence of $\mathrm{Cl}^{-}$ion, on the type and characteristics of the potential program, namely triangular sweep or potential step and on the cation in solution, since the incorporation of the latter in the complex layer should alter its water content and ionic composition. This is apparently the case of $\mathrm{Ca}^{2+}$ ions as compared to $\mathrm{Na}^{2+}$ in the passivation of iron in base solutions as concluded from previous work[3].

Acknowledgements - This work was financially supported by the Consejo Nacional de Investigaciones Científicas y Técnicas and the Comisión de Investigaciones Científicas de la Provincia de Buenos Aires. This work was partially supported by the Regional Program for the scientific and technological development of the Organization of the American States.

\section{REFERENCES}

1. G. Nazri, E. Yeager and B. D. Cahan, Tech. Rep. No. 1, Proj. NR SRO-009/7-30-79, Case Western Reserve University, Cleveland (1981).

2. K. E. Heusler, In Encyclopedia of Electrochemistry of the Elements (Edited by A. J. Bard), Vol. 9A, pp. 229-381, Marcel Dekker, New York (1982).

3. O. A. Albani, J. O. Zerbino, J. R. Vilche and A. J. Arvia, Electrochim. Acta 31, 1403 (1986).

4. M. Froelicher, A. Hugot-Le Goff, C. Pallotta, R. Dupeyrat and M. Mason, in Passivity of Metals and Semiconductors (Edited by M. Froment), pp. 101-105 Elsevier, Amsterdam, (1983).

5. J. Dünnwald, R. Losy and A. Otto, In Passivity of Metals and Semiconductors (Edited by M. Froment), pp. 107-112 Elsevier, Amsterdam, (1983).
6. J. Dünnwald and A. Otto, Z. Anal. Chem. 319, 738 (1984).

7. Z. Q. Huang and J. L. Ord, J. electrochem. Soc. 132, 24 (1985).

8. T. Zakroczymski, C. J. Fan and Z. Szklarska-Smialowska, J. electrochem. Soc. 132, 2862 (1985).

9. S. Haupt, C. Calinski, U. Collisi, H. W. Hoppe, H. D. Speckmann and H. H. Strehblow, Surf. Interface Anal. 9 , 357 (1986).

10. C. Gutièrrez and M. A. Martinez, J. electrochem. Soc. 133, 1873 (1986).

11. S. Juanto, J. O. Zerbino, J. R. Vilche and A. J. Arvia, In Surfaces, Inhibition, and Passivation (Edited by $\mathrm{E}$. McCafferty and R. J. Brodd), pp. 226-238 The Electrochemical Society, Pennington, (1986).

12. T. Zakroczymski, C. J. Fan and Z. Szklarska-Smialowska, J. Electrochem. Soc. 132, 2868 (1985).

13. M. G. Alvarez and J. R. Galvele, Corros. Sci. 24, 27 (1984).

14. N. Sato and K. Kudo, Electrochim. Acta 16, 447 (1971).

15. N. Sato, Boshoku Gijutsu 23, 535 (1974).

16. O. A. Albani and J. R. Vilche, in preparation.

17. J. R. Vilche and A. J. Arvia, Proc. 7 th Intern. Congr. Met. Corros., Rio de Janeiro, pp. 245-256 (1978)

18. R. S. Schrebler Guzmán, J. R. Vilche and A. J. Arvia, Electrochim. Acta 24, 395 (1979).

19. V. A. Macagno, J. R. Vilche and A. J. Arvia, J. Appl. Electrochem. 11, 417 (1981).

20. R. S. Schrebler Guzmán, I. R. Vilche and A. I. Arvia, $J$ Appl. Electrochem. 11, 551 (1981).

21. M. E. Vela, J. R. Vilche and A. J. Arvia, in Passivity of Metals and Semiconductors (Edited by M. Froment), pp. 59-65 Elsevier, Amsterdam, (1983).

22. M. E. Vela, J. R. Vilche and A. J. Arvia, Electrochim. Acta 31, 1633 (1986).

23. J. O. Zerbino, J. R. Vilche and A. J. Arvia, J. Appl. Electrochem. 11, 703 (1981).

24. M. E. Vela, J. R. Vilche and A. J. Arvia, J. Appl. Electrochem. 16, 490 (1986).

25. V. Jovancicevic, J. O'M. Bockris, J. L. Carbajal, P Zelenay and T. Mizuno, J. electrochem. Soc. 133, 2219 (1986).

26. R. Goetz, B. MacDougall and M. J. Graham, Electrochim. Acta 31, 1299 (1986).

27. M. Janik-Czachor and S. Kaszczyszyn, Werkstoffe u. Korros. 33, 500 (1982). 